\title{
City design: what went wrong at Milton Keynes?
}

published as

Edwards, M (2001) 'City design: what went wrong at Milton Keynes?'

Journal of Urban Design 6(1): 73-82

Michael Edwards

The Bartlett School

University College London

22 Gordon Street

London WC1H OQB

02067974874

m.edwards@ucl.ac.uk

http://www.bartlett.ucl.ac.uk/planning

Few plans are implemented exactly as they are conceived. Often this is a mercy, as Michael Hebbert has so thoroughly argued for the long history of London (1998).

Professional navel-gazing about what happens between plan and actuality is always salutary and ought to be a normal part of our practice - just as we expect the medical profession to analyse the outcomes of its procedures.

This note argues that the new city of Milton Keynes was largely developed in ways which produced a much worse built environment than had been envisioned by the initial design team, of which the author was a member. It ends up by reflecting on whether we could have written or drawn the initial plan in ways which could have led to a better outcome or whether the plan was a victim of social and economic forces which could not realistically have been foreseen, vanquished or moulded. Because the account is essentially personal, it is written partly in the first person, which I hope the reader will accept. $^{1}$

The new city of Milton Keynes was designated by the Minister of Housing and Local Government, Richard Crossman, in 1967. A consultant planning team

\footnotetext{
${ }^{1}$ I am grateful to John de Monchaux, now at MIT, for suggesting I should write this lecture down. His, and others', versions of events are recorded in Clapson et al (1998).
} 
was appointed at once by the newly-constituted Development Corporation in order that a master plan could be developed while the Corporation built up its own staff capacity to implement the plan. The firm of Llewelyn Davies, Weeks, Forestier-Walker and Bor was appointed with numerous sub-contractors, notably North American transport engineers Pete Marwick Kates and Co and economists Nathaniel Lichfield and Associates in which I was working at the time. Richard Llewelyn Davies headed his firm, Walter Bor was partner in charge and John de Monchaux was full-time team leader ${ }^{2}$. The story is well known.

The macro-structure of the master plan was a grid of roads at roughly $1000 \mathrm{~m}$ spacing, with land uses widely distributed in a coarse zoning plan across the entire designated area. This plan purported to be 'deduced' from a series of abstract policy 'goals' put to the Board and approved at the outset - an approach regarded at the time as quite an advanced way of working ${ }^{3}$. The grid structure was designed ...

- to be easily comprehensible and navigable,

- to permit unconstrained use of the motor car,

- to avoid the inefficiencies and costs of tidal flows between home and work which arise where jobs are in a single work area,

- to offer residents a choice between private and public transport,

- by mixing homes with workplaces, shopping, educational and other services, to create at least the potentiality for people to make short trips, and to have a choice of service centres to use, and

- to contribute to pedestrian safety by ensuring that all roads were either clearly for car priority (the grid) or for pedestrian priority (the local roads). This was based on research showing that pedestrians were most at risk on intermediate kinds of roads - then known as 'local distributor roads' - which were therefore to be avoided (Levin and Bruce, 1968).

2 Richard Llewelyn Davies died in 1981; Walter Bor in 1999 while I was writing this and before I could send a copy for his comments.

${ }_{3}$ These goals were (i) opportunity and freedom of choice (ii) easy movement and access and good communications (iii) balance and variety (iv) an attractive city (v) public awareness and participation and (vi) efficient and imaginative use of resources. The allegedly deductive approach as part of rational comprehensive planning was criticised at the time as a sham (Gutch, 1970). 
Two other factors were on the agenda. One was the team leaders' determination to bury an earlier plan by Bucks County planner Fred Pooley, a design with 4 monorail loops connecting living areas as beads on strings with a central work and service zone: a plan prioritising public transport and subordinating cars. Mr Pooley was a member of the Board of the Corporation and his ideas thus had to be circumvented in a diplomatic way ${ }^{4}$. An early proposal from Nathaniel Lichfield and myself for a systematic cost benefit study comparing the two approaches met a frosty response within the team and was probably never put to the Board. But this is a digression.

The other tension in the master planning was about shopping. Whereas the logic of the plan was to distribute all services widely over the urban area, every version of the master plan showed one dominant centre. Though very much aware of the tendency of retailing to over-concentrate, we considered that a strong set of comparison goods retailers could only be attracted to the town if they and their customers had the benefit of this agglomeration. The Board members considered 'a centre' as essential to the image and identity of the town. So in it went, without controversy but with a number of problems in its wake, as we shall see.

A distinctive approach to how the city would grow on its grid was a part of the planning from the outset. A number of team meetings considered the policies, technical standards and design possibilities for the articulation of localities: housing form, density and tenure, shopping, schools, libraries and social services, clinics, pedestrian, cycle, car and bus movement, emergency access, open space and so on. At a crucial stage one team member was asked to take everything away and integrate it over the weekend. That team member was the young Francis Tibbalds and he produced such a triumph of synthesis, with diagrams, charts and sketches illustrating a lucid, elegant, hand-written text that it was xeroxed as it stood for the Board, without typing ${ }^{5}$.

\footnotetext{
${ }^{4}$ This story is told by Bendixson and Platt (1992) who had access to the Board's minutes, and is the subject of critical comment by Colin Ward (1993).

${ }^{5}$ I cannot track down a copy of this document. Any reader who can find one should make sure it reaches a safe archive.
} 
The resulting guidelines for the development of localities were, in my view, highly innovative and are summarised below. This is a 1999 summary, not a contemporary one ${ }^{6}$. I have tried to avoid bias as far as I can but am intentionally emphasising features which seem more important in hindsight than they appeared at the time.

(i) The grid of main roads would have speed limits of $30 \mathrm{mph}(50 \mathrm{~km} / \mathrm{h})$, traffic light control at main cross-roads and synchronisation to permit most cohorts of traffic to flow through successive lights on green.

(ii) With these vehicle speeds, it would be safe and feasible to have sideturnings every few hundred metres $-3,4$ or even 5 turnings in the typical $1000 \mathrm{~m}$ stretch between cross-roads - and traffic flows on each turning would be reduced to safe levels.

(iii) Drivers would thus be able to pull off the road for shopping, school and other business.

(iv) Buses could safely stop beside the main roads, both at cross-roads (for interchange) and at intermediate points where they would typically connect with footpath systems.

(v) Densities of development, for housing and other activities, would be highest along these grid roads, especially between the cross-roads, and would fall off to the lowest densities in the centre of each grid square where buildings with big gardens, allotments, playing fields and parks would mostly be found.

(vi) The positions on main roads, mid-way between the cross-roads, would be the nodes for services with various combinations of schools, shops, libraries, clinics, workplaces and so on.

(vii) This strategy seemed a robust way of trying to sustain good local shopping in the face of the concentration and centralisation trends evident in modern retailing. It was explicitly envisaged that shops could draw on passing trade as well as on local pedestrians and that, where a local convenience store folded, the premises could attract other viable retail or non-retail use. (This was a conscious rejection of the practice common in earlier new town

${ }^{6}$ The contemporary version, with strong input from Mike Macrae, is in the master plan (MKDC 1970, Vol1 and Llewelyn-Davies et al 1970, Vol2 ). 
and local planning of clumping development in distinct 'neighbourhoods' and planning a 'centre' tucked away within each.)

(viii) Residents would thus be able to choose between at least 4 such service centres within $1000 \mathrm{~m}$ and between a much larger number using cycle, car or bus.

(ix) Traffic noise on such a grid road system would be modest, so adjoining buildings would enjoy reasonable peace and quiet. Only at main cross-roads would noise levels justify any separation of buildings from the grid.

Moving through Milton Keynes would thus be an experience very similar to moving though a typical European town, built with little formal planning over the last centuries: commerce and services on main roads, housing and employment clustered around the most accessible points and lines, density falling away behind. Your nearest service cluster is close. If you want a different food shop, a different school or a squash court you may need to carry on to the next one. Although the macro-grid does not lend itself very well to public transport, the combined effect of these local design principles did as much as could be done in that context to make the bus network direct (by staying on the main roads) and well patronised (through the bunching of densities along the routes). The wide range of local building densities from multi-storey flats and offices through to very low densities around golf courses, lakes and allotments had both an aesthetic and a social intent: it was part of a strong rejection of the notorious uniformity of 2-storey houses in earlier new towns and part of a strategy to attract not just the newly-forming households of skilled workers but a more diverse range of age groups, social class and ethnicity. This was an attempt to engineer a way round a another perceived failing of earlier new towns.

These development principles and intentions were embedded in the master plan handed over to the Development Corporation, and its new professional staff, in 1970.

A number of major changes were soon made to the plan, and others took effect during the implementation process. 
The most important changes flowed from the Corporation's immediate rethinking of the road system. They decided to re-design the main grid to operate without an urban speed limit - thus at speeds of 60-70 mph (95-110 $\mathrm{km} / \mathrm{h}$ ). This brought many design changes:

(a) Traffic lights were replaced with roundabouts, British style, at most crossroads, and usually with a slight rotation so each road would kink slightly on entering and leaving.

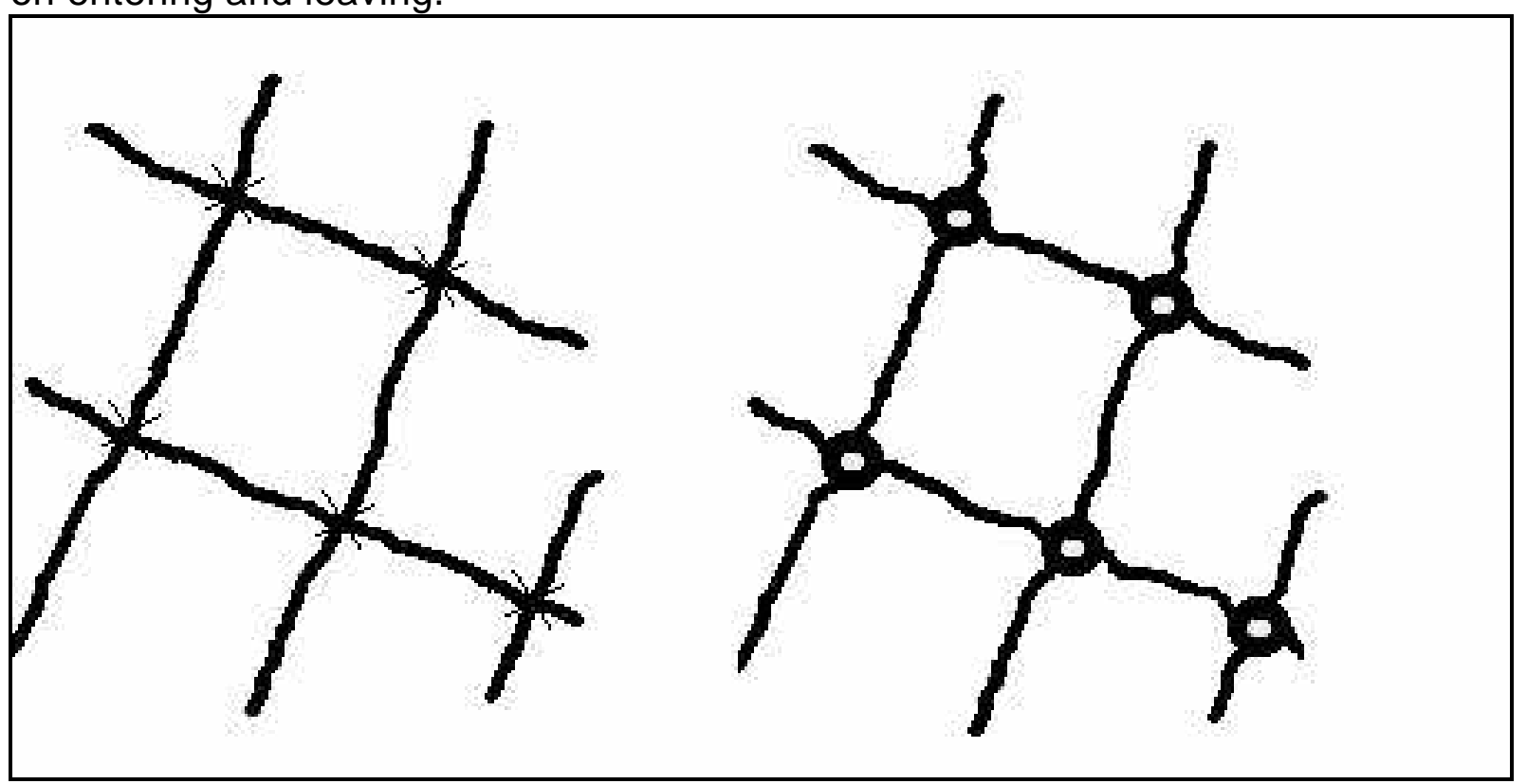

In each of these pairs of caricatures the original intention is on the left, the outcome as built on the right.

(b) Very few side turnings could safely be permitted: only 1 or at the most 2 in a $1000 \mathrm{~m}$ stretch. 


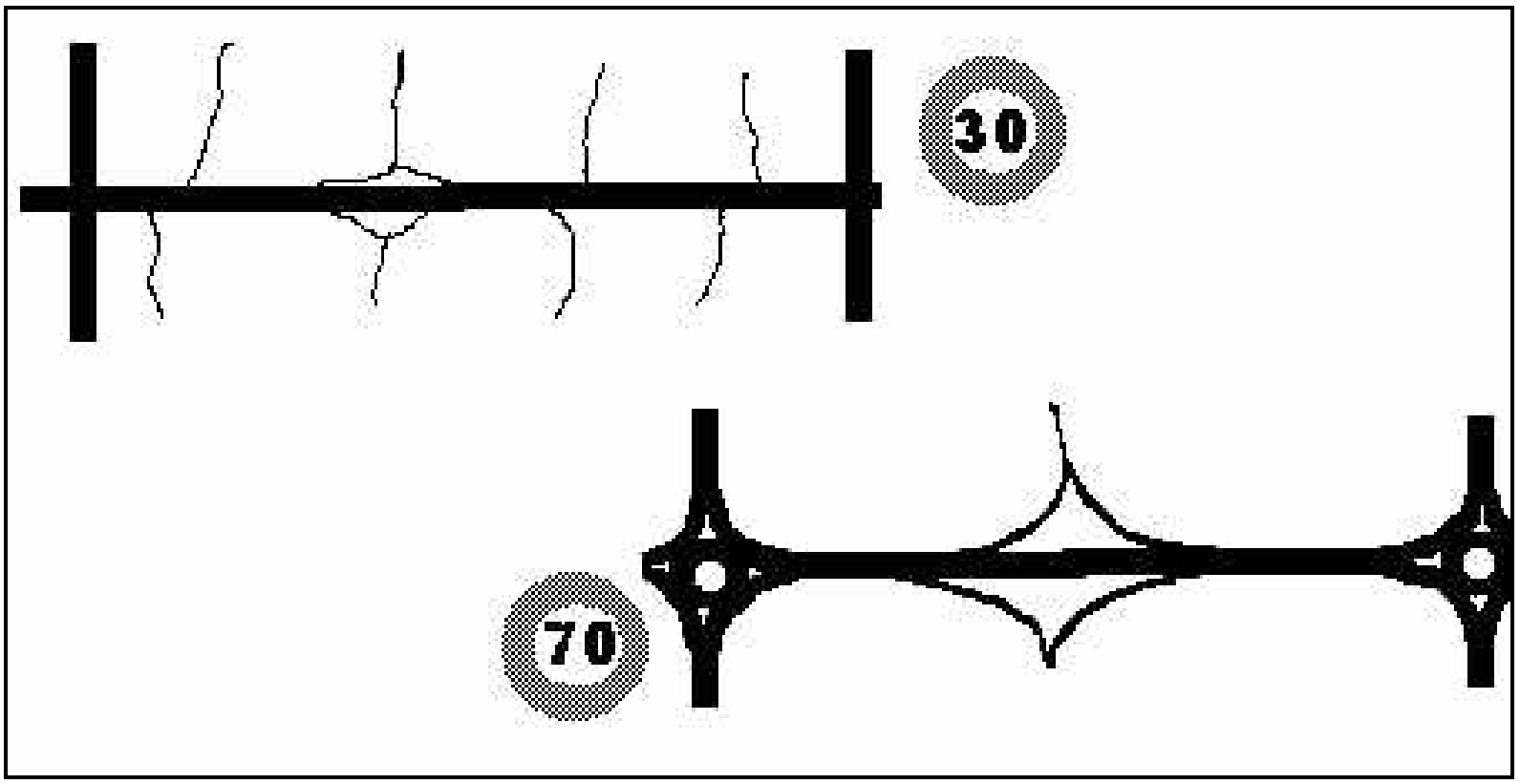

(c) Neither cars nor buses could safely be allowed to pull to the side of the main roads and stop: instead they would have to leave by slip roads and stop within the grid-squares. Bus routes thus became longer and circuitous.

(d) Land reservations for main roads were greatly enlarged to fit the acceleration and deceleration lanes and to separate built-up areas from the-now much noisier-roads.

(e) As a further measure against noise, a great deal of earth mounding and massive planting was added along the grid roads.

The effect of these transport changes was reinforced by a complete change in the parcelling, design and naming of development sites.

(f) The intention had been that the normal unit for design and for development operations would be centred on the main grid road at the mid-point between crossroads: 


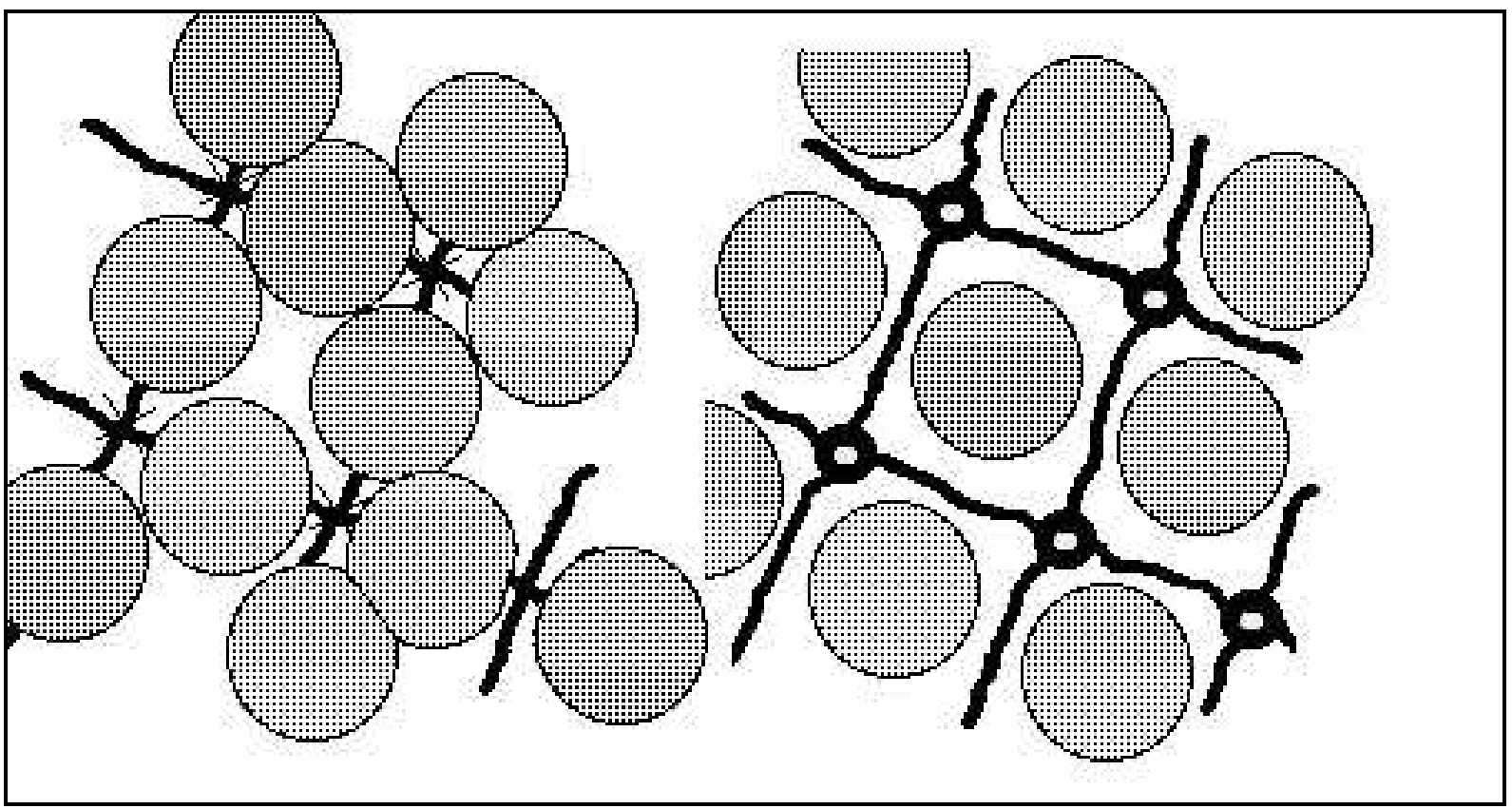

(g) Local shopping and service centres were pushed away from the grid road frontages, becoming embedded in the edges-or occasionally in the middle —of the development parcels. Retailers could thus no longer expect significant passing trade, and few even enjoyed visibility from the main roads.

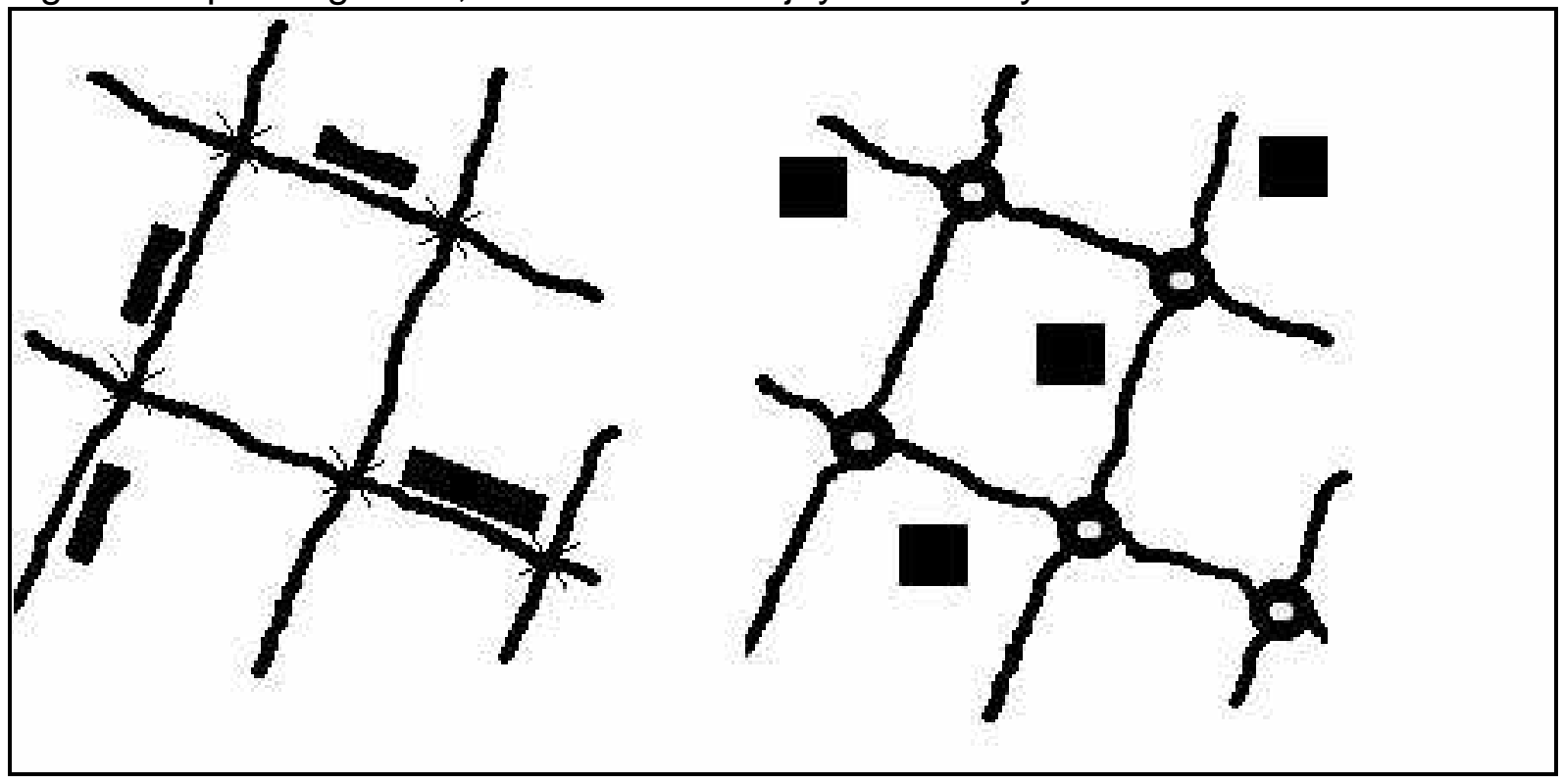

(h) The interior of the grid square thus became the typical design unit; most squares had just one design team, one developer, one name (and one post code). The practical and conceptual building block of the city was thus not the bead on the string but the lozenge lying within the high-speed grid of roads. 


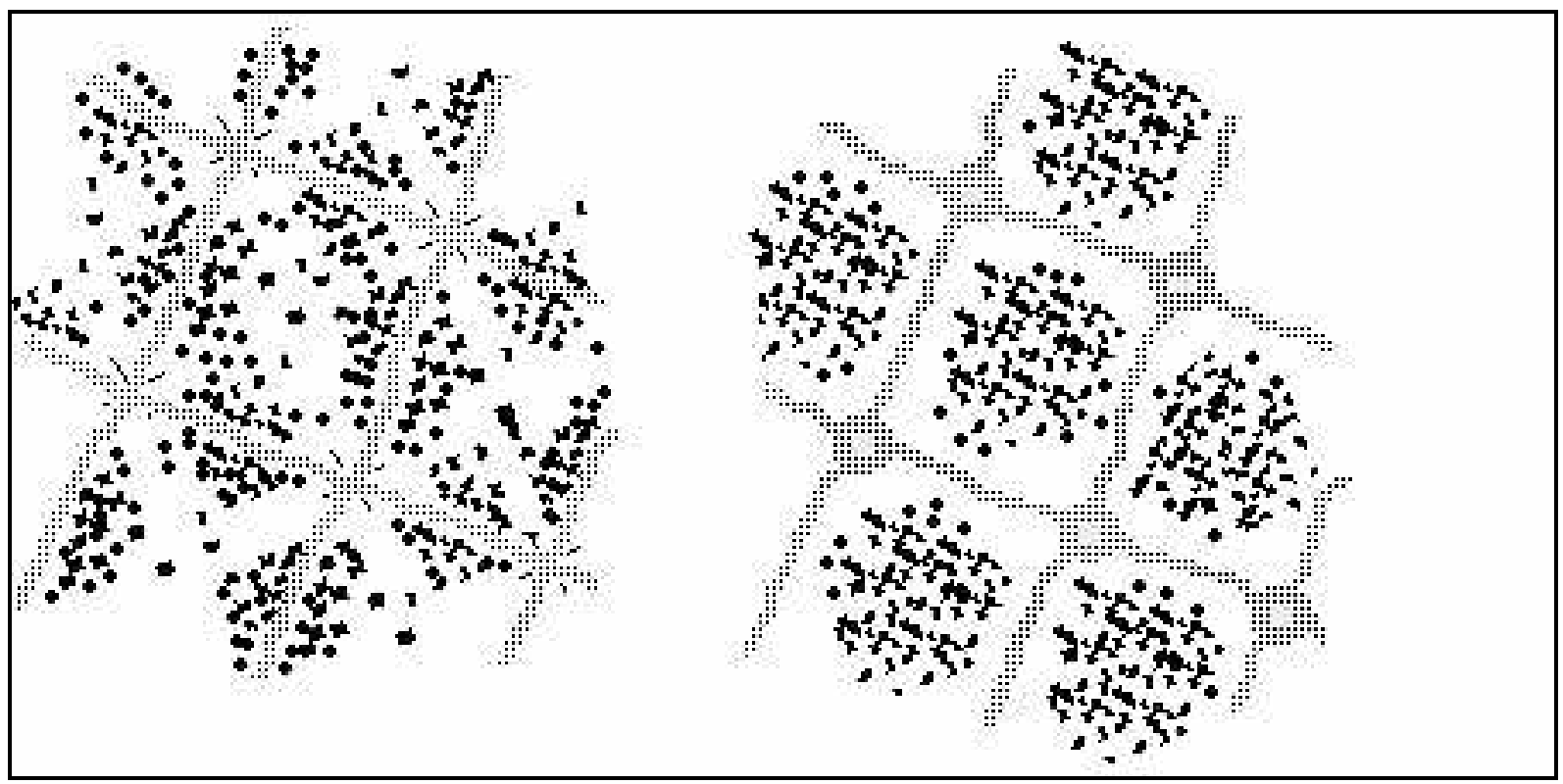

Further damage flowed from features of the housing development process, public and private. Whereas the earlier new town corporations had built (and retained ownership of) most of their housing, by 1969 the Labour government-under pressure from the IMF-was already calling for the involvement of private capital and the reduction of state expenditure. They had also been advised that a mix of tenures in new towns was desirable in a report commissioned from J B Cullingworth and V A Karn (1968). This pressure was reflected in Corporation policy, so private developers were invited to bid for the development of a lot of the housing. Despite pressure from the Corporation, these developers resisted calls to build at a range of local densities, citing their judgements of marketability. Most of the private housing estates were thus built at very homogeneous suburban densities. Some blocks of flats were built, but usually as separate projects on separate sites. Some relatively low-density housing was also produced - but also as separate projects in what became quite luxurious grid squares, separated from the main middle-market developments.

A very similar fate befell the social housing. We had persuaded the Corporation that they would only have a chance of meeting their social mix objectives if about half the housing were built as social housing. Here the density problem flowed not from marketing considerations but from the extreme rigidity with which the DoE enforced the density-based cost controls 
used across the country to control council house building, the Housing Cost Yardstick (DoE 1971). This instrument effectively forbade the production of housing at low local densities or (except in established cities) at high local densities. We argued strongly that this rule system was (a) not based on real evidence of actual costs and (b) not relevant in the MK context because the Corporation had so much flexibility in how it could account for (and recoup) its general development expenses of land servicing and infrastructure. DoE would not budge, however, so the social housing at MK was mostly designed and built within much the same narrow range of local densities as in the rest of the UK ${ }^{7}$.

One other unexpected factor contributed to this catalogue of problems: the rapid development of MK's main shopping centre. The master plan had called for the rather gradual development of this centre in order that sub-centres and local shops could have the best chance of becoming established. In the event the Corporation formed a partnership with the Post Office Staffs Superannuation Fund, then Britain's largest pension scheme, to develop the central shopping building and completed about 100,000 m2 in a single phase. The building is a superb Miesian structure, designed by David Walker, Chris Woodward and others in the MKDC office. It integrates shops (though no other uses), parking and servicing in a supremely elegant and light design which was, and has remained, a great success. It rapidly became - in effect — the regional mall for a wide area, drawing customers from Northampton, Oxford, Bedford and beyond, even bus tours from London. This gratified the Board, happy to see Milton Keynes quickly 'on the map', and meant that the citizens quickly came to enjoy superb comparison shopping, much better than the early residents of the first new towns. The downside, however, was quite adverse conditions for planners and retailers to create and sustain strong subcentres and local shopping. The battle to resist retail over-concentration was effectively lost.

For all these reasons I submit that Milton Keynes is not the place it might have been. The view from the road-the experience of getting around-is in fact

\footnotetext{
${ }^{7}$ We later learned that the DoE was at that time withholding publication of research they had commissioned from Prof P A Stone, a sequel to his Urban Development in Britain, Vol 1, which would apparently have added strong support to our argument.
} 
what you see when speeding along expressways, lined with fine planting, with occasional slip-roads off to named, but invisible, neighbourhoods, workplaces and services. Buses follow circuitous routes and are thinly patronised. Most local shopping centres struggle to maintain viability, tucked away and dependent on their designed 'catchment areas'. Pedestrian routes are often segregated from the roads and the typical resident may have quite a long walk to the bus, often through woodland which can be dripping and rather scary. Travel is overwhelmingly by car (especially for men) with buses tending to carry women and children. The segregated cycle paths work well, however, and redeem the situation for many people, especially older children and young adults.

How do we attribute responsibility for this very poor outcome-this disaster, in my judgement?

Part of the blame is quite clearly ours for the way we wrote and drew the master plan. It was much less forceful, less clear and less passionate than it could and should have been. Memory tells me that we tried to write more firmly but the text was watered down, on the principle that the plan should be more flexible, less prescriptive. Walter Bor has since told me that it was Richard Llewelyn Davies who finally insisted on this flexible presentation.

The initial planning team-and especially myself-should take responsibility for two failures to anticipate and work around market forces. We should have realised how reluctant Britain's notoriously conservative volume housebuilding firms would be to vary their densities and we should have devised land policies and pricing strategies along with tough design briefs to enforce compliance. Equally, although we foresaw the risks of weak local retailing, we should have created much stronger instruments and tenure arrangements to fight the trend.

A further failing was in the drawing. The key drawing in the master plan is almost ambiguous-certainly not very explicit-about the interdependent design principles listed (at i-ix) above. This aggravated the weakness of the prose. 
Some of the responsibility lies with the structural relationship of consultant and client. For one group to prepare a plan and hand it over to another group for implementation is a recipe for trouble (though there may be benefits as well). The transformation of the road designs and of the land parcelling were part of a process whereby the professionals in MKDC—some newly appointed and none in post more than 2 years-were making the plan their own. As the initial planning team we were consulted about the road changes and we responded very critically indeed, but evidently to no effect.

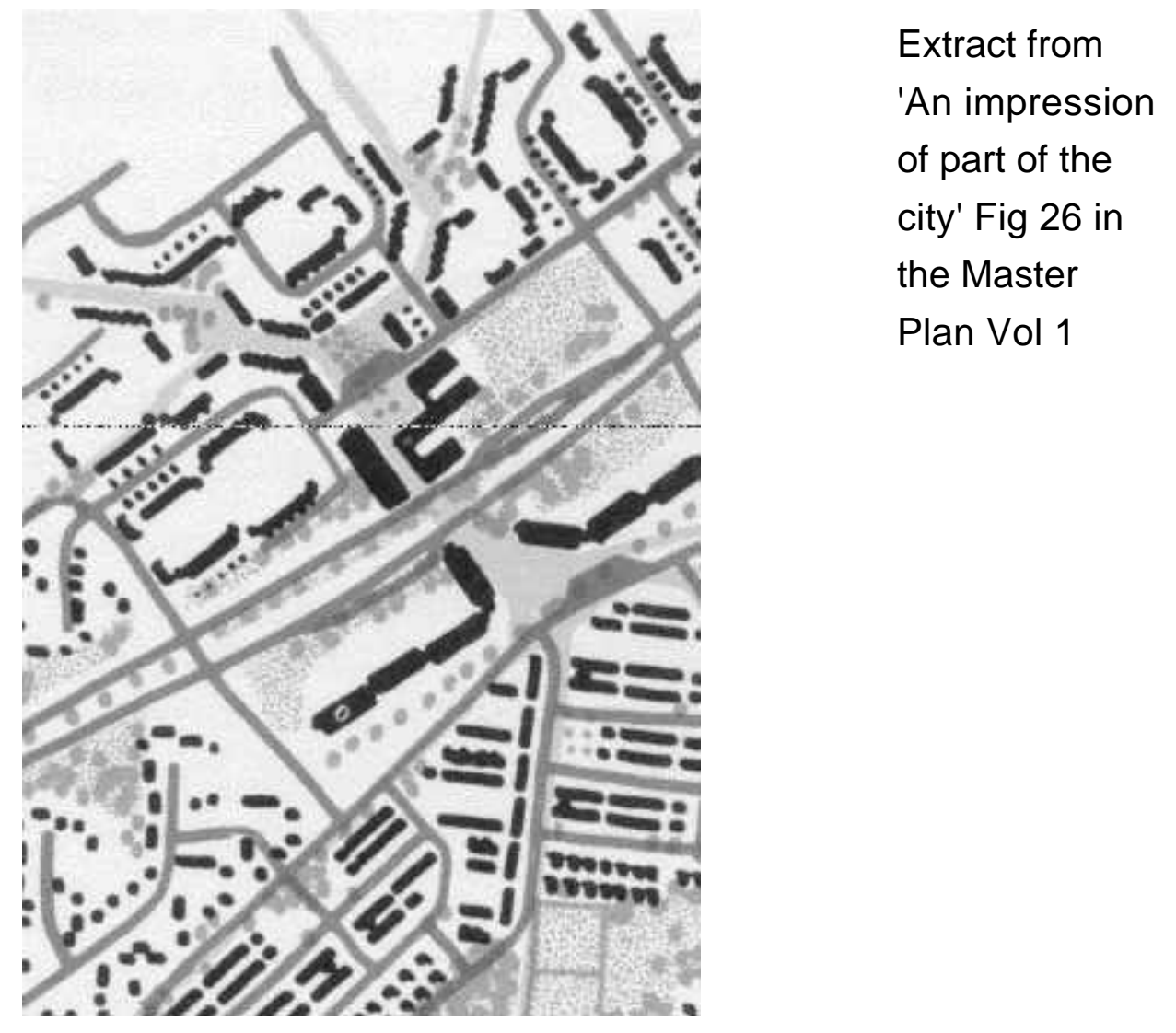

Finally some responsibility lies with the DoE and its new towns division - so much weaker than its French counterpart. The Department could and should have relaxed the stranglehold of the Housing Cost Yardstick over housing density. Its officers could also have acted to keep the adopted plan on track and resist the catastrophic changes described here. 
'Flexibility' is one of the many dangerous nostrums in planning and is usually deployed very selectively. The planning team and the Corporation were naive to adopt a plan so 'flexible' in these respects. It contrasts with the Board's alacrity in building a single gigantic sewage works to ensure that MK would always have 'spare capacity' and thus to avert the risk that its expansion would be prematurely stopped, as it could have been with the more 'flexible' sewage disposal options which the Board rejected.

Can we turn the clock back? Clearly not for Milton Keynes, even if there were support for my point of view. Some elements of the criticisms made here have been taken on board in the planning of later stages of the City (Bendixson and Platt, 1993, 177) but to limited effect. Perhaps, though, there is scope for trying out the full original version in new areas as the city continues to grow under the millennial imperative of the government's thrust to expand housing supply. Perhaps there is also scope to 'retro-fit' some of the lost elements. We could try...

- replacing roundabouts with lights,

- straightening out the junctions to improve orientation,

- reducing speeds to $30 \mathrm{mph}$ on the grid,

- re-cycling some of the green areas along the main roads (space which David Pritchard has named SLOAP ${ }^{8}$ ) for dense development with lay-bys, service bays, shops and so on.

The combination of tough design briefs, the relatively mature local property market and the slightly more creative outlook of today's private and social developers might make it financially and technically feasible. Much would depend on who now owns the SLOAP since the privatisation of New Town assets.

These are reflections by someone who was involved at the outset but not since then (save as an embarrassed and disoriented visitor). If other

\footnotetext{
${ }^{8}$ An interesting model is the re-planning of Ballymun in Dublin by McCormack, Jamieson and Pritchard, building new frontage development on the green bits of land beside roads which David Pritchard (2000) calls SLOAP - the Space Left Over After Planning. 
participants, residents or historians can identify errors of fact or interpretation I hope they will do so. But if I am right then we need to reflect the conclusions in the practice and the teaching of planning and design. To me, the most significant lessons are

1. We need to spell out the logic of design arguments with maximum clarity and rigour in plans, briefs and guidance. Keep 'flexibility' in its place, echoing the Quakers' bossy motto 'In essentials unity, in non-essentials freedom'.

2. Avoid relying on lofty and empty abstractions (choice, flexibility, diversity in the 1970s, sustainability today). These words may have to be used in building consensus but unless they are elaborated into precise desiderata they are dangerous hostages to fortune. In modern jargon MK could be considered a success in terms of an ill-defined 'sustainability': certainly there is a great deal of biomass and urban wildlife. Cycling facilities are superb. On the other hand the design as built does not 'sustain' local shops or other services nearly as well as it should, it works against the use of public transport, helping to 'sustain' a car-dependent way of life and gender-inequalities in mobility. And if the original prognosis was right, it will have generated avoidable pedestrian accidents. Finally the long distances between housing of different densities, tenures and prices will not have 'sustained' the local social mixing which the initial plan rightly sought.

3. We need to be much more skilled in anticipating how the private property development process will operate under a variety of foreseeable scenarios and planning rule-systems. There is now a lot of theoretical and empirical work which can enable us to do this well and there is no excuse for us getting it wrong.

\section{References}

Bendixson, T and J Platt (1992) Milton Keynes: image and reality Cambridge, Granta Editions

Clapson, M, M Dobbin and P Waterman, Eds. (1998) The Best Laid Plans, Milton Keynes since 1967 Luton, University of Luton Press 
Cullingworth, J B, and V A Karn (1968) The Ownership and Management of Housing in the New Towns London, HMSO

DoE (1971) Housing Cost yardstick, Circular 18/71 (annual)

Gutch, R E (1970) Goal Formulation, Thesis, MPhil, University of London UCL Hebbert, M (1998) London: more by fortune than design Chichester, Wiley Levin, P H, and A J Bruce (1968) The location of Primary Schools, Building Research Station, referred to in Llywelyn-Davies et al 1970 Vol 2 p 303 Llewelyn-Davies, Weeks. Forestier-Walker and Bor (1970) The Plan for Milton Keynes, Vol 2, London, LLDWFWB Milton Keynes Development Corporation (1970) The Plan for Milton Keynes, Vol 1, Milton Keynes. MKDC

Pritchard, D (2000) 'On the edge: regenerating a Dublin suburb' CITY4(1): 65-80

Stone, P A (1970) Urban Development in Britain: standards, costs and resources 1964-2004. Volume 1 Population Trends and Housing Cambridge, CUP

Ward, C (1993) New Town, Home Town: the lessons of experience London, Calouste Gulbenkian Foundation 